\title{
Exploring the Organizing Patterns of Doings of the Material Process in Tamil: A Systemic Functional Linguistics Approach
}

\author{
Markandan Rubavathanan ${ }^{1,2}$ \\ ${ }^{1}$ Department of Public Administration, Uva Wellassa University, Badulla, Sri Lanka \\ ${ }^{2}$ College of Foreign Languages and Cultures, Xiamen University, Xiamen, China \\ Email: ruban@uwu.ac.lk
}

How to cite this paper: Rubavathanan, M. (2021). Exploring the Organizing Patterns of Doings of the Material Process in Tamil: A Systemic Functional Linguistics Approach. Open Journal of Social Sciences, 9, 191-206.

https://doi.org/10.4236/jss.2021.96016

Received: May 8, 2021

Accepted: June 20, 2021

Published: June 23, 2021

Copyright $\odot 2021$ by author(s) and Scientific Research Publishing Inc. This work is licensed under the Creative Commons Attribution International License (CC BY 4.0).

http://creativecommons.org/licenses/by/4.0/ (c) (i) Open Access

\begin{abstract}
The study endeavours to explore the organizing patterns of doings of the material process in Tamil. For that, this research accounts a brief description of the lexicogrammatical resources of DOING PROCESS TYPE of Tamil which is potentially concerned with modelling the representing patterns of experiential meanings realised through the transitive model of the TRANSITIVITY SYSTEM. The principal objective of this paper is to describe the resources in Tamil by approaching Systemic Functional Linguistics theory. By underlying this theory, researcher is able to identify, understand and explain the organisation of doings of the material process of Tamil in asking questions about how language is configured for use and how that configuration is representing, creating and exchanging meaning in a social setting. In terms of the description, a number of different texts are collected from spoken and written discourses in Tamil. This corpus-based and theory-based research is comprehensive and accompanied by the combination of qualitative and quantitative methods. Such approach achieved through the exploration will be presented in detail as the domain of doing process type by means of the system network. This study provides both Tamil speaking community and systemic functional linguists with insights into the basic organizations and variations of doing process type of Tamil in order to use in their different language applications and implementations.
\end{abstract}

\section{Keywords}

Doing Process, Material Process, Transitivity, Experiential Function, Tamil

\section{Introduction}

In traditional grammar of Tamil language, describing language in the sense is understood as collecting, transcribing, and analysing linguistic data then identi- 
fying, categorizing and explaining them asking what are the minimum meaningful units Tamil has to form an absolute meaningful word, phrase and clause and how those units are functioning grammatically and lexically in that absolute "parts of speeches". Basically last two thousand years, Tamil grammarians have been working on more detailed classifications of lexical categories and grammatical categories accordingly to the "grammar of Tamil". At the same time, from 1960s many Tamil linguists have been influenced by Chomsky's "universal"-transformational and generative-grammar and imposed the model of structural description of English to describe Tamil. So there are a large number of "formal" descriptions available in the field of Tamil linguistics (Kothandaraman, 1977; Annamalai \& Steever, 1998; Agesthialingom, 2003; Nuhman, 2013). But the experience with the description of Tamil language based on various theories in the past of course had shown that those undertaking was not quite enough to understand and describe the "resources" of Tamil language.

The Systemic Functional Linguistics (SFL) approach is gradually being recognized as providing a very suitable, explanatory and applicable theoretical concept and multidimensional framework for viewing language as a resource for meaning-making (Halliday, 2006, 2009). Basically, as parts of the name of the theory denote, language is systemic and functional; the language to express meanings is explained in the interrelated systems and functions. According to Halliday and Matthiessen (2014) the overall functions of language are three, formulated by meanings and overall organizations of language. The three kinds of functions are simultaneous in the system that has evolved as "Interpersonal", "Ideational", and "Textual"; these are combined as Metafunctions of language which is one of the basic concepts around which the theory is constructed. On the basis, the SFL approach to language means investigating how language is organized and it is seeking the nature of language in functional terms (Halliday, 1973; Matthiessen, Teruya, \& Lam, 2010; Bartlett \& O’Grady, 2017).

It is, therefore, needed a description of Tamil language based on SFL theory to investigate, understand and explore the "resources" of Tamil language in order to see how people use language with each other in achieving everyday social life and think through how those resources are organized, functioned and realized in the text for making-meaning, and also, to find how the grammatical (clause) patterns of system of DOING PROCESSES differ from each other on modelling experiences in Tamil. Accordingly, this study explores the organizing grammatical patterns of DOING of the material processes of the ideational meanings realised through the transitive model of the TRANSITIVITY SYSTEM of Tamil. The accounts developed in this way for a detailed and delicate description of the experiential metafunction and the mapping of its resources in the lexicogrammar generalised in the PROCESS TYPE models as proposed by Halliday (1994) and Halliday and Matthiessen (2014).

\section{Theoretical Framework}

The theoretical framework is implemented by locating language description with 
respect to the multidimensional concepts by means of global dimensions: stratification, instantiation and metafunction and local dimensions: rank and axis (Halliday, 2006, 2009; Matthiessen, 2004, 2012; Matthiessen \& Halliday, 2009; Halliday \& Matthiessen, 2014). Accordingly, it locates lexicogrammar with respect to stratification of semiotic systems into strata; then it moves with a view on instantiation from the overall potential to their deployment of lexicogrammatical resources; it subsequently moves to the metafunctional organizations of clausal resources; then the rank scale is concerned with the local organisation of resources of Tamil within the stratum of lexicogrammar; then the axial dimension is undertaken as the main guiding concept underlying the interdependency of system and structure.

So, the exploration of doing processes of Tamil has to build on the basis of the fundamental notions, theoretical concepts, mechanics, and multidimensional framework of Systemic Functional Linguistics Theory (SFLT). The theoretical approach is gradually being recognised as providing a very suitable descriptive framework for viewing language as a meaning making resource (Caffarel, Martin, \& Matthiessen, 2004; Teruya, 2007). Because, a number of basic theoretical concepts and multidimensional framework complementarily constitute the theoretical architecture as a whole, which together seek to explain how language works and what people do with language.

A number of renowned researchers have contributed to inspire more studies into how language is used (Martin, 2004; Mwinlaaru \& Xuan, 2016). Accordingly SF theoretical approach to language has become important tools to understand language in use (Eggins, 2004; Thompson, 2014). Webster emphasized that "the linguist's description of language at work must be grounded in a theory of how language works, i.e., general linguistic theory, providing both a theory of grammar and a theory of lexis. Grammar is what powers language; it is where the work is done" (Webster, 2015: p. 10).

Therefore, the study applies the theoretical framework with descriptive categories to the description of particular Process Type of the systems of TRANSITIVITY. It is intended to investigate mainly the DOING PROCESS in order to realize the organizations of the grammar of Tamil can be used to construe meaning. Besides it aims to distinguish the functional and lexicogrammatical elements of clauses in DOING PROCESS. For that reason system-structure is taken as the fundamental relationship between theoretical and descriptive categories. The dispersal of system-structure relation allows an appreciation of the organisation of DOING PROCESS of Tamil in its own terms and places the foundations for more systemic comparison of grammatical patterns across languages. And also, this study intended to provide an impact to the studies of language in use, and to function as a base for further work on systemic functional grammar of the Tamil and also it may be applied principally with many language-based activities as a powerful tool.

\section{Data}

SFL theory has always drawn to some extent on "language-in use" both written 
and spoken text as the source for its application on a particular language descriptions and explanations (Bloor \& Bloor, 2004). In terms of the description of experiential grammar of Tamil, especially analysing the configuration of the Doing Process types has required a number of different text. Accordingly, the doing process types are formulated with the data collected from spoken and written discourses in Tamil. This corpus-based and theory-based research is comprehensive and accompanied with the combination of qualitative and quantitative methods. Such approach achieved through the exploration will be presented in detail the domains of process type by means of the system and structure.

\section{Material Processes in the Transitivity System}

Our experience of the world of doing and happening around us-including actions, activities, and events are construed by the grammar of material processes (Halliday, 1994; Matthiessen, 1999; Halliday \& Matthiessen, 2014). These processes typically construe some kind of unfolding and dynamic physical actions and a quantum of change in the flow of events in the world as taking place through entities acting in space and time with some input of energy which is needed to initiate the process. Thus, the configurations of material processes express the meaning that some entity does something.

According to Halliday (1994: p. 110), material processes are processes of doing or happening: doing types express the notion that some entity materially does something, which may be done to some other entity-may extend to affect another entity or not; and happening types express the notion that something is happening or happened. These processes can be probed with the happening clauses asking "what is happening or what happened to the entity?" and from the doing clauses asking "what did the entity do or what did the entity do to the other entity?". Entities are called as participants whose may be thing or phenomena of our experience such as animate and inanimate or even abstractions. As a result, it can be said that material processes are not only concrete but also abstract.

Material process construes and organises the phenomena of experience into wholes and their elements, which help out to view the clause from the notions of the system of TRANSITIVITY, ERGATIVITY/AGENCY or CAUSATIVITY and CIRCUMSTANCES. Material process type of the system of TRANSITIVITY has distinct clause configurations with its certain functional elements. Clauses with a material process obligatorily have elements and optionally or additionally can have elements as,

1) Process-verb/verbal group is an action verb such as catch, run, replace, open

2) inherent participant-Actor/Middle is a noun/nominal group

3) additional participant(s)—Goal, Beneficiary (Recipient/Client), Range/Scope

4) circumstance(s)

e.g. 1. Dog is whining

Part: Pro: Mat

e.g. 2. Rowling is writing a novel 
Part: 1 Pro: Mat Part: 2

e.g. 3. Father bought this toy for my brother at Walmart yesterday

Part: 1 Pro: Mat Part: 2 Part: 3 Cir: 1 Cir: 2

In the examples above, e.g. 1 has two elements-one process and one participant and e.g. 2 has three elements-one process and two participants while e.g. 3 has six elements-one process, three participants and two circumstances.

In material clauses, in general, there should be a process that can be a doing or a happening and a participant the source of the energy bringing about the change is called the Actor. In addition, material processes can have one or two participants who may or may not impacted by the involvement in the process which are labelled as Goal, Beneficiary (Recipient/Client), Range/Scope. Furthermore, material clauses may also consist of certain inherent phenomena which are construed as circumstances expand the process (cf. Halliday \& Matthiessen, 2014).

The configurations of these elements possibly will represent semantic figures sorted out by lexicogrammar of a language as distinct subtypes of material processes. At the same time, the grammar of language can configure more delicate distinctions within the subtypes. Therefore, it is obvious that there are possibilities to recognize the most delicate processes within the material grammar of Tamil systemically. Consequently, this chapter explores some of the characteristics identified and the lexicogrammatical resources of the material processes in Tamil language, particularly in the domain of doing, happening and behaving.

\section{Material Processes in Tamil}

As briefly reviewed and generally outlined about the notion of material process in the previous section, the particular configurational relations of elements which are associated with specific experiential functions in the lexicogrammatical structure of Tamil material clauses allow the realization of distinct process subtypes.

The primary distinction within material processes is between figures of doing, behaving and happening. These figures cover the most delicate sub-types of the processes. These processes typically construe the changers in the flow of events around the consciousness of human beings. The basic paradigmatic-systemic representation available to the grammar of Tamil in the option of material transitivity is shown in Figure 1. The less delicate system network of material process can be read out as follows: one may choose between three types of material processes: doing, behaving and happening. If the option "doing" is chosen, then the term may be either middle or effective. If the option "effective" is chosen, then one may choose "creative" or "transformative" and so on.

There are specific lexicogrammatical criteria that distinguish material processes from other main processes: mental, verbal and relational. The major distinction concerning "doings", "behaving" and "happenings" in Tamil material clauses can be probed with the general processes sey or pannu (do) for "doings" and "behaving" and nada or nikal (happen) for "happenings" respectively, as illustrated in Table 1. 


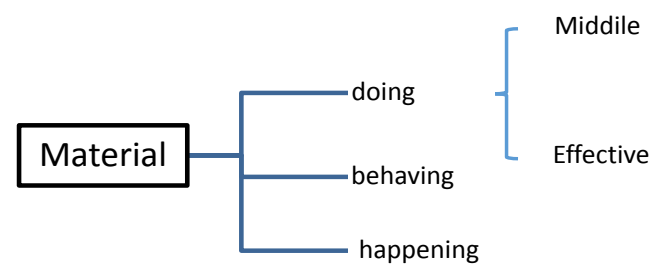

Figure 1. The system network of some of the less delicate of material options.

Table 1. Probes associated to material process in Tamil: sey and nada.

\begin{tabular}{|c|c|c|}
\hline aval enna seykiraan? & aval paalsoru samaikkiraal & material: doing \\
\hline What is she doing? & She is cooking milk-rice & (transitive) \\
\hline avan enna seykiraan? & avan aattil neenthukiran & material: doing \\
\hline What is he doing? & He is swimming in the river & (intransitive) \\
\hline avarkal enna seykiraarkal? & avarkal sirikkiraarkal & material: behaving \\
\hline What are they doing? & They are laughing. & (intransitive) \\
\hline enna nadakkirathu? & malai peykirathu & material: happening \\
\hline What is happening? & it is raining & (intransitive) \\
\hline
\end{tabular}

At the lexicogrammatical level, processes (verbs/verbal groups) of these Material processes in Tamil are defined as some sort of actions or happening which is usually concrete, physical, tangible and abstract; for example samai "cook", neenthu "swim", siri "laugh", veddu "cut", thira "open", vilu "fall", oudu "run", eluthu "write", anuppu "send". These processes can be divided into doing, behaving and happening. Further, this variance is made into distinctive subtypes because of the choice of lexical verbs. Because, many verbs construe different experiences with number of morphological forms: verb + morpheme or verb + morpheme + auxiliary + morpheme (see example below). The verb forms help to identify the subtypes of material processes and interpret the overall TRANSITYVITY system-transitive and ergative models. Here, the verb forms are only used to describe material processes from the transitive perspective.

e.g. 4

a. Material: happening - thira - open

\begin{tabular}{ll}
\hline kathavu & thiranthathu \\
door & opened \\
Actor/Medium & Pro \\
The door opened & \\
\hline
\end{tabular}

b. Material: doing - thira - open

\begin{tabular}{lll}
\hline Kalyani & kathavai & thiranthaal \\
Kalyani & door & opened \\
Actor & Goal & Pro \\
Kalyani opened the door & & \\
\hline
\end{tabular}

e.g. 5 
a. Material: doing: middle - nira $+\mathrm{mb}-$ fill

\begin{tabular}{lll}
\hline thoddi & neeraal & nirambiyathu \\
tank & with water & filled \\
Actor/Medium & Cir & Pro \\
The tank filled with water & \\
\hline
\end{tabular}

b. Material: doing: effective - nira + pp - fill

\begin{tabular}{llll}
\hline Vivasaayi & thoddiyai & neeraal & nirappinaan \\
farmer & tank & with water & filled \\
Actor & Cir & Pro \\
The farmer filled the tank with water & & \\
\hline
\end{tabular}

It is acceptable that these kind of material process are considerably extensive than any other process types in Tamil (according to Matthiessen (1999, 2014), around $60 \%$ of verbs come about as material processes in English). The set of verbs of material clause in Tamil language contrasts with other process options, particularly the relational, verbal, and mental ones. Within material processes, doing types are realized by a fairly extended set of verbs, whereas both behaving and happening types are realized by a limited set of verbs. Since the lexicogrammatical resources for construing material experiences is wide-ranging, the configurations of that processes also have to be in the same way wide-ranging. However, the lexis and the grammatical principles and the systemic characterizations of other types of TRANSITIVITY (AGENCY and CIRCUMSTIANTIAL) of Tamil are adopted to find out the most delicate options of material processes.

The material clause is modelled at least with two fundamental elements as Process + the Participant inherent in that process-the Actor in doing and happening and Behaver in behaving. The Actor or the Behaver is the doer- the one doing the material activities or the affected-the one affected through the process realized by nominal group in the nominative case. Generally, the Actor/Behaver is the source of the energy bringing about the change in material clauses. In Tamil, Actor/Behaver typically has a triggering agreement with the finite Process in which the final suffix unmarks the actor's identities such as thinai (rational/irrational), person, gender, number, politeness. In Tamil language, the most nuclear element in the material clause is the Process which is realized by the verbal group that is typically located at the end of the clause. The other elements-participants and circumstances precede the process.

$$
\text { e.g. } 6-\mathrm{a}
$$

\begin{tabular}{ll}
\hline kannaadi & udainththathu \\
glass & broken \\
Actor & Pro \\
The glass was broken &
\end{tabular}


e.g. 6 -b

\begin{tabular}{lll}
\hline thambi & kannadiyai & udaiththaan \\
Brother & glass & broke \\
Actor & Goal & Pro: Mat \\
\hline
\end{tabular}

In Tamil, material processes of doing, behaving and happening potentially have Participants with the attendance of Circumstances. Depending on the types of material process-effective or middle clauses-there may be up to three participants (including the inherent participant Actor/Behaver) involved in the process: Goal, Beneficiary (Recipient or Client) and Range (Scope or Behaviour). These participants are realized by nominal group which are marked by case markers. The Goal is that which is created, affected, impacted, changed, displaced, destroyed by the Actor's involvement in the Process. Actor may create the Goal or either changes its position or its status. Furthermore, material processes realising doings can have an additional participant such as Beneficiary or Scope and behavings can have Behaviour while happenings can have Range in the Actor-Process nucleus. Though, the system of material process is Actor centred, the configuration of Actor-Process frame can be expanded between Actor and Process by including other participant(s). The orbital configurations of material process can be mapped out by Table 2 .

As shown above, the modelling of Material processes of the transitive model of the system of TRANSITIVITY are organized as a configuration of a process, an inherent participant, additional participants and circumstances. The organization of inherent components (Actor + Process or Actor + Goal + Process) in the material processes reflects the traditional grammatical accounts of Tamil Vaakkiyam - sentence: transitive (seyappaduporulkuntraa vaakkiyam) and intransitive (seyappaduporulkuntriya vaakkiyam). The central variable of this categorization is whether the Process (typically verb) extends to impact another Participant (seyappaduporul-things which are processed/done-Goal in SFL) or not. If the clause is organized as a configuration of Actor + Process with Goal, the clause is transitive; and if the clause is organized only as a configuration of Actor + Process without Goal, the clause is intransitive. According to the traditional view of transitivity in Tamil grammar, each and every clause obligatorily has a doing (process - payanilai) and a doer (Actor - eluvaay - participant) and some clauses can have a second participant, Goal (seyappaduporul).

Table 2. Typical configurations of the material process.

\begin{tabular}{llll}
\hline Actor/Behaver & Process & & \\
Actor/Behaver & Range & Process & \\
Actor & Goal & Process & \\
Actor & Range & Goal & Process \\
Actor & Beneficiary & Goal & Process \\
\hline
\end{tabular}


This traditional modelling is suitable to describe only a number of the figures of the material process of Tamil but not all other types of transitivity system. Because, in SFL material processes with a Goal, Beneficiary and Range are divided into certain subtypes. But the traditional primary distinction between transitive and intransitive or effective and non-effective can help to characterize the major types of material process in which doing processes basically can be either effective or middle while behaving and happening can only be middle.

\begin{tabular}{lll} 
e.g. 7.-a & & \\
\hline Jayaraj & veedu & kaddinaan \\
Jayaraj & house & built \\
Actor & Goal & Pro: Mat: doing \\
eluvaay & seyappaduporul & payanilai \\
Jajaraj built a house & &
\end{tabular}

\begin{tabular}{ll} 
e.g. 7.- b & \\
\hline Vannak Kilikal & parakkinrana \\
Colourful parrots & fly \\
Actor & Pro: Mat: happening \\
eluvaay & payanilai \\
The colourful parrots are flying &
\end{tabular}

The configuration of Material clause concerned with Process and Participants that are nuclear in nature. As shown above the Process-Participant nucleus can be expanded by other Participant roles. Away from this, other elements also may be added in the configuration such as Circumstances. In principle, Circumstances are attending on the nucleus configuration for representing experiential functions and help to augment the process as well as relating to nuclear configurations as a whole. In Tamil, like other languages, more than one Circumstance is possible within a material process at different points, by different kinds. On the other hand for construing particular material processes, the attendance of certain Circumstances may be necessary. With the attendance of certain Circumstances, nuclear configurations of material process are further specified.

Circumstances can be realized by adverbial group, nominal groups and postpositional phrases. Nominal groups and postpositional phrases are marked by particular morphemes such as -oudu, udan (Accompany), -aal (instrument) -il, idam, ku (special and temporal) -aaha (cause). These morphemes may realize various functions in Tamil material processes: for an example a circumstance element with nominal group plus "ku" relates to place, then it is a "spatial", if time then it realizes a "temporal", but if it is a conscious being then it is Participant who can either a "recipient" or a "client". 


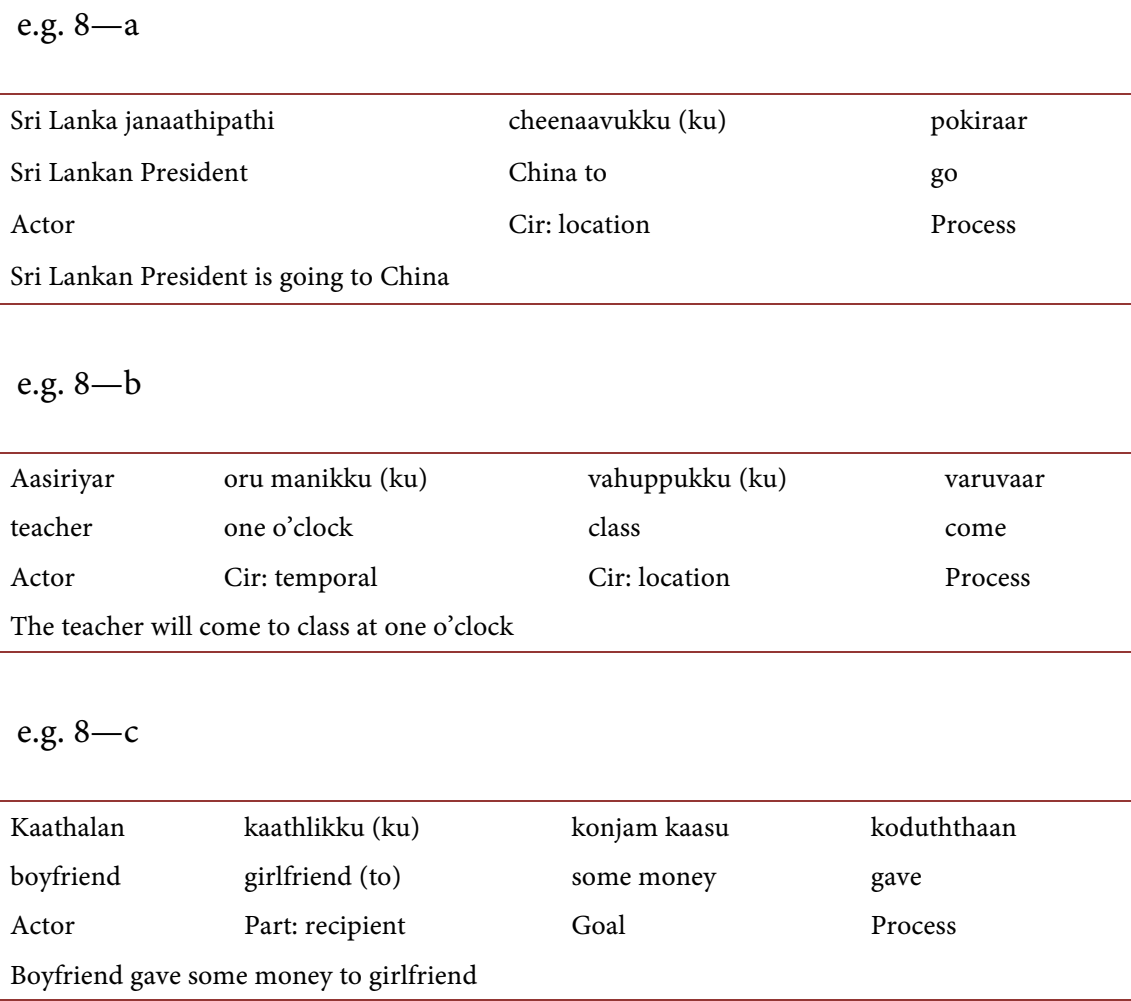

Another distinctive criterion relates to the choice of unmarked tense of material process. Because, major processes of the PROCESS TYPES unfold through time and the way the process unfolds may be different from one to another. In particular, material processes tend to differ from all the other types. The unmarked present tense of material process in Tamil is the simple present (e.g. seykiraan - dose, seykirom - do) since it usually involves dynamic verbs. But in English, the unmarked present tense selection is the present-in-present (e.g. is/am/are doing-the progressive/continuous) (Halliday, 1994; Matthiessen, 1999; Halliday \& Matthiessen, 2014). The following examples (e.g. 8 and e.g. 9) are expressing that how present tense is realized in Tamil.

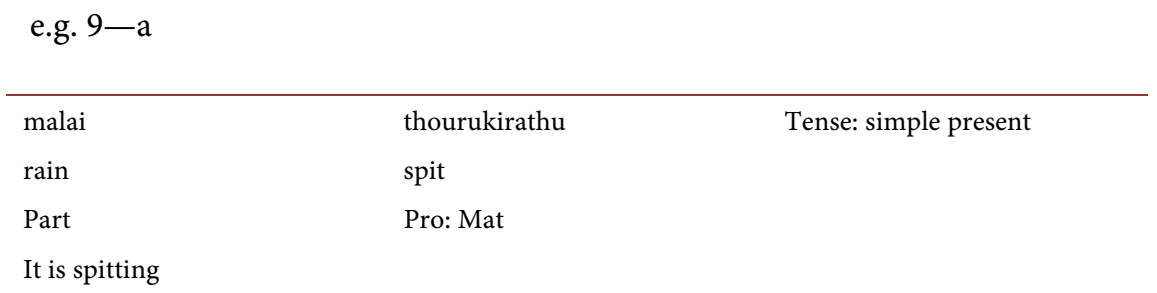

e.g. $9-b$

\begin{tabular}{|c|c|c|}
\hline kulanthai & alukirathu & Tense: simple present \\
\hline Baby & cries & \\
\hline Part & Pro: Mat & \\
\hline Baby is crying & & \\
\hline
\end{tabular}


e.g. $9-c$

\begin{tabular}{llll}
\hline Arul & kanitham & padikkiraan & Tense: simple present \\
Arul & Mathematics & studies & \\
Part & Part & Pro: Mat & \\
Arul is studying Mathematics & & \\
\hline
\end{tabular}

e.g. $9-d$

\begin{tabular}{|c|c|c|c|c|}
\hline ippothu & enathu appa & paal theneer & kudikkiraar & Tense: simple present \\
\hline \multirow[t]{2}{*}{ Now } & my father & milk tea & drinks & \\
\hline & Part & Part & Pro: Mat & \\
\hline
\end{tabular}

\section{Configurational Analysis of Doing Process}

Doing processes embody the major subtype of material processes. Doing process typically construe the unfolding of dynamic activities in the world outside the consciousness of human beings. These activities represent those of doings which can be concrete or abstract (Halliday \& Matthiessen, 2014). This notion differs from the Tamil grammatical tradition where all verbs are defined as "doing-sey/pannu" verbs such as writing, thinking, scratching, telling, cleaning, and playing and so on.

According to SFL literature, these doing type processes express the notion that some entity does something or some entity dose something to some other entity (Halliday, 1994; Halliday \& Matthiessen, 2014). That is to say that the entities are acting/doing something to them or others with the input of energy. Doings/actions involve Participants who can initiate the Process as a doer or can be impacted by that process. In Tamil Processes are realized by the typical action verbal group (sey/pannu-doing-verbs) and Participants are realized by the nominal group. So clauses with doing processes obligatorily have a process (doing) and a participant (doer) which is termed as Actor.

The Actor is the one initiating the Process as a doer. In general, there is no semantic restriction on the class of nominal group realizing the Actor role, unlike the roles of Sayer in verbal processes and the Senser in mental processes which will be discussed in the following chapter. In Tamil-like other many languages, Actor construes the energetic entity that can be an animate (uyarthinai) or an inanimate (ahuthinai) entity as shown in example (10) below. These animate and inanimate objects can be either a concrete entity-material, visible, solid, physical, tangible, touchable, and existing-or an abstract entity-metaphysical, theoretical, beliefs, concept, qualities, characteristics and non-existent.

e.g. 10a-Material: doing (configuration: Actor -+ Process) 


\begin{tabular}{ll}
\hline Soorya & oudukiraal \\
Soorya & runs \\
Actor (animate) & Pro: \\
Soorya is running & \\
\hline
\end{tabular}

e.g. 10b-Material: doing (configuration: Actor + Range + Process)

\begin{tabular}{lll}
\hline Aasiriyar & paadasaalaikku & vanthuviddaar \\
Teacher & school & has come \\
Actor (animate) & Range & Pro: \\
Teacher has come to school & & \\
\hline
\end{tabular}

e.g. 10c-Material: doing (configuration: Actor + Range + Process)

\begin{tabular}{lll}
\hline $\begin{array}{ll}\text { suttulaappayanikal } \\
\text { tourists }\end{array}$ & $\begin{array}{l}\text { Sigiriya malai uchchikku } \\
\text { top of the Sigiriya mountain }\end{array}$ & $\begin{array}{l}\text { erinaarkal } \\
\text { claimbed }\end{array}$ \\
Actor (animate) & Range & Pro: \\
Tourists climbed the top of the Sigiriya mountain & \\
\hline
\end{tabular}

e.g. 10d-Material: doing (configuration: Cir + Actor + Ben: Client + Range + Process)

\begin{tabular}{|c|c|c|c|c|}
\hline intru maalai & naangal & ilankaikkaaka & uthaipanthu & vilaiyaadappokirom \\
\hline today evening & we & for Sri Lanka & football & play + going \\
\hline Cir: Time & Actor (animate) & Beneficiary: Client & Range & Pro: \\
\hline \multicolumn{5}{|c|}{ Today evening we are going to play football for Sri Lanka } \\
\hline \multicolumn{5}{|c|}{ e.g. 10e-Material: doing (configuration: Actor + Goal + Process) } \\
\hline Jesu & \multicolumn{3}{|c|}{ ainthu appangalaiyum irandu meengalaiyum } & eduththaar \\
\hline Jesus & \multicolumn{3}{|c|}{ the five loaves and the two fish } & took \\
\hline Actor (animate) & \multicolumn{2}{|l|}{ Goal } & & Pro: \\
\hline \multicolumn{5}{|c|}{ Jesus took the five loaves and two fish } \\
\hline
\end{tabular}

e.g. 10f-Material: doing (configuration: Actor + Goal + Process)

\begin{tabular}{lll}
\hline Mahintha Chinthana & naaddai & abiviruththiseythathu \\
Mahintha Chinthana & country & developed \\
Actor (abstract-concept) & Goal & Pro: \\
The Mahinda Chinthana developed the county & \\
\hline
\end{tabular}

e.g. 10g-Material: doing (configuration: Actor + Ben: Client+ Goal + Process) 


\begin{tabular}{|c|c|c|c|c|}
\hline arasaangam & \multicolumn{2}{|c|}{ kuraiatha varumaanamulla kudumbangalukku } & veedukal & kaddikkoduththathu \\
\hline The government & \multicolumn{2}{|c|}{ for low income families } & homes & built \\
\hline Actor (abstract) & \multicolumn{2}{|l|}{ Beneficiary - Client } & Goal & Pro: \\
\hline \multicolumn{5}{|c|}{ The government built homes for low income families } \\
\hline \multicolumn{5}{|c|}{ e.g. 10h-Material: doing (configuration: Cir + Actor + Cir + Goal + Process) } \\
\hline 2004 lil & aalipperalai & ilankaiyil & iennaikalai & aliththathu \\
\hline in 2004 & Tsunami & Sri Lanka & coconuts & destroyed \\
\hline Cir: Time & Actor (inanimate) & Cir: Place & & Pro: \\
\hline
\end{tabular}

e.g. 10i-Material: doing (configuration: Actor + Cir + Goal + Process)

\begin{tabular}{llll}
\hline naay & thanathu ejamanin vayalilirunthu & sila paravaikalai & thuraththiyathu \\
dog & from his master's paddy field & some birds & chased away \\
Actor (animate) & Cir: Place & Goal & Pro: \\
Dog chased away some birds from his master's paddy field & \\
\hline
\end{tabular}

e.g. 10j-Material: doing (configuration: Actor + Ben: Client+ Goal + Process)

\begin{tabular}{llll}
\hline Amma & engalukku & appam & sudukiraar \\
Mom & us & hoppers & makes \\
Actor (animate) & Beneficiary: Client & Goal & Pro: \\
Mother is making hoppers for us & &
\end{tabular}

e.g. 10k-Material: doing (configuration: Actor + Ben: Recipient + Goal + Process)

\begin{tabular}{llll}
\hline Pirathama virunthinar & maanavarukku & parisil & valanginaar \\
The chief guest & students & prize & gave \\
Actor (animate) & Beneficiary: Recipient & Goal & Pro: \\
The chief guest gave away the prize to students &
\end{tabular}

The above examples are typical of their configuration in terms of their transitivity selections, with a predominance of material processes representing doing. In those clauses, both animate and inanimate Actors are participating in actions and they are having control over their actions and the power to impact on other entities/things. In all clauses Actor, as the source of energy initiates the process and brings about the change through time, leading to an outcome (Halliday \& Matthiessen, 1999: p. 148, 2004: p. 282). But, in the examples (10a, 10b, 10c, \& $10 \mathrm{~d}$ ) the outcome is confined to the Actor itself (Soorya, aasiriyar, suttulaap- 
payanikal, and naangal). Whereas, in other examples (10e, 10f, 10g, 10h, 10i, 10j \& 10k) the outcome is extended to the other Participant-the Goal. In those processes, the Actor (Jesu, Mahintha Chinthana, arasaangam, aalipperalai, naay, Amma, and Pirathama virunthinar) is doing something to to the Goal (ainthu appangal irandu meengal, naadu, homes, pala thennaikal, sila paravaikal, appam and parisil).

If the Actor does not affect another Participant in a clause that is middle, if it is affecting another participant-Goal that is effective. Because from a transitive perspective of SFL, these doing processes are not restricted in agency, that is to say, they can be either middle or effective (Halliday, 1994: p. 168). Thus some doing clauses can have the configuration of Actor + Process and some clauses can have the configuration of Actor + Goal + Process. Based on this Actor's affecting, then the simultaneous system of doing processes is entered: 1) Middle 2) Effective. Accordingly, the clauses 10a, 10b, 10c, \& 10d are middle whereas the clauses $10 \mathrm{e}, 10 \mathrm{f}, 10 \mathrm{~g}, 10 \mathrm{~h}, 10 \mathrm{i}, 10 \mathrm{j} \& 10 \mathrm{k}$ are effective.

Moreover, the middle and effective doing processes can be divided according to the involvement of the additional participants such as Beneficiary (Client/Recipient) or Range. A middle doing clause can have one or two additional participants in the configuration with Actor + Process. It can be configured with one additional participant-Range as Actor + Range + Process (like in e.g. 10b \& 10c) or two additional participants-Range and Beneficiary as Actor + Beneficiary + Range + Process (like in e.g. 10d). In the same way, an effective doing clause can have one or two additional participants in the configuration with Actor + Goal + Process. The effective clause can be configured as Actor + Client + Goal + Process (like in e.g. $10 \mathrm{~g} \& 10 \mathrm{j}$ ) or as Actor + Recipient + Goal + Process (like in e.g. 10k). The Participants-Actor, Goal, Range, Client or Recipient are very specific to doing processes where those participants are functioning with particular role. Even though the concerned participant in the nuclear doing process is the Actor, the other participants are also taking part in extending the process and giving the answer to the question of whether the doing process extends beyond the Actor or not.

\section{Conclusion}

The SFL theoretical approach to explore the doing process of the Tamil illustrates the configurations-organizing patterns-of the same. As shown above, the system-structure is the core theoretical concepts from which the organization patterns of language are explored through the integrated dimensions of axes, metafunctions, stratification, instantiation and rank. That is to say, SFL theory has the necessary resources to investigate all the lexicogrammatical choices-patterns available to the Tamil users in order to make meanings in the doing process. According to SFL, the components of the configurations are regarded as having function and not form (Halliday, 1994: p. F39). This implies that the choices chosen by Tamil language user to make meaning may bring 
some significant account to the description of a system of doing. Accordingly these structural differences are important for both delicate network of a transitive model and an ergative model of the system of doing. In view of that those structures from the system of doing can be illustrated accordingly. By investigating Tamil language through SFL theory, this study has described the grammatical patterns of DOINGS and their meanings comprehensively. These finding can be found out as the resources of Tamil grammar for making meaning of DOINGS. Further, this extensive description can more effectively contribute to the kind of difficulties and problems emerging in particular grammar of Tamil. At the same time it puts the foundations for more systematic comparison of grammatical patterns within Tamil and across languages.

\section{Conflicts of Interest}

The author declares no conflicts of interest regarding the publication of this paper.

\section{References}

Agesthialingom, S. (2003). Thamil moli amaippiyal (Structure of Tamil Language). Sithamparam: Meyyappan Thamizhaaivakam.

Annamalai, E., \& Steever, S. B. (1998). Modern Tamil. In S. B. Steever (Ed.), The Dravidian Languages (pp. 100-128). London: Routledge.

Bartlett, T., \& O'Grady, G. (2017). The Routledge Handbook of Systemic Functional Linguistics. London: Routledge. https://doi.org/10.4324/9781315413891

Bloor, T., \& Bloor, M. (2004). The Functional Analysis of English: A Hallidayan Approach (2nd ed.). London: Arnold. https://doi.org/10.4324/9780203774854

Caffarel, A., Martin, J. R., \& Matthiessen, C. M. I. M. (2004). Language Typology: A Functional Perspective. Amsterdam: John Benjamins. https://doi.org/10.1075/cilt.253

Eggins, S. (2004). An Introduction to Systemic Functional Linguistics (2nd ed.). London: Continuum.

Halliday, M. A. K. (1973). Explorations in the Functions of Language. London: Edward Arnold.

Halliday, M. A. K. (1994). An Introduction to Functional Grammar (2nd ed.). London: Edward Arnold.

Halliday, M. A. K. (2006). Systemic Theory. In K. Brown (Ed.), Encyclopaedia of Language and Linguistics (2nd ed., pp. 443-448). Boston, MA: Elsevier. https://doi.org/10.1016/B0-08-044854-2/02051-4

Halliday, M. A. K. (2009). Methods Techniques Problems. In M. A. K. Halliday, \& J. J. Webster (Eds.), Continuum Companion to Systemic Functional Linguistics (pp. 59-86). London: Continuum.

Halliday, M. A. K., \& Matthiessen, C. M. I. M. (1999). Construing Experience through Meaning: A Language-Based Approach to Cognition. London: Continuum.

Halliday, M. A. K., \& Matthiessen, C. M. I. M. (2014). Halliday's Introduction to Functional Grammar (4th ed.). London and New York: Routledge. https://doi.org/10.4324/9780203783771

Kothandaraman, P. (1977). The Verb in Modern Tamil. Madras: Pulamai Publications. 
Martin, J. R. (2004). Metafunctional Profile of the Grammar of Tagalog. In A. Caffarel, J. R. Martin, \& C. M. I. M. Matthiessen (Eds.), Language Typology: A Functional Perspective (pp. 255-304). Amsterdam: John Benjamins. https://doi.org/10.1075/cilt.253.07mar

Matthiessen, C. M. I. M. (1999). The System of Transitivity: An Exploratory Study of Text-Based Profiles. Functions of Language, 6, 1-51. https://doi.org/10.1075/fol.6.1.02mat

Matthiessen, C. M. I. M. (2004). Descriptive Motifs and Generalization. In A. Caffarel, J. R. Martin, \& C. M. I. M. Matthiessen (Eds.), Language Typology: A Functional Perspective (pp. 537-673). Amsterdam: John Benjamins. https://doi.org/10.1075/cilt.253.12mat

Matthiessen, C. M. I. M. (2012). Systemic Functional Linguistics as Applicable Linguistics: Social Accountability and Critical Approaches. DELTA: Documentação de Estudos em Lingüística Teórica e Aplicada, 28, 437-471. https://doi.org/10.1590/S0102-44502012000300002

Matthiessen, C. M. I. M. (2014). Extending the Description of Process Type within the System of Transitivity in Delicacy Based on Levinian Verb Classes. Functions of Language, 21, 139-175. https://doi.org/10.1075/fol.21.2.01mat

Matthiessen, C. M. I. M., \& Halliday, M. A. K. (2009). Systemic Functional Grammar: A First Step into the Theory. Beijing: Higher Education Press. https://www.researchgate.net/publication/265398862

Matthiessen, C. M. I. M., Teruya, K., \& Lam, M. (2010). Key Terms in Systemic Functional Linguistics. London: Continuum.

Mwinlaaru, I. N., \& Xuan, W. W. (2016). A Survey of Studies in Systemic Functional Language Description and Typology. Functional Linguistics, 3, 1-41. https://doi.org/10.1186/s40554-016-0030-4

Nuhman, M. A. (2013). Adippadait thamil ilakkanam (Basic Tamil Grammar). Colombo: Poobalasingam Book Depot.

Teruya, K. (2007). A Systemic Functional Grammar of Japanese (Vol. 1 \& 2). London: Continuum.

Thompson, G. (2014). Introducing Functional Grammar (3rd ed.). London: Routledge. https://doi.org/10.4324/9780203785270

Webster, J. J. (2015). Understanding Verbal Art: A Functional Linguistic Approach. Heidelberg: Springer. https://doi.org/10.1007/978-3-642-55019-5 